\title{
COMPLICAÇÃO NA EXODONTIA DE TERCEIRO MOLAR SUPERIOR INCLUSO: DESLOCAMENTO PARA O SEIO MAXILAR - RELATO DE CASO
}

Maria Izabel Sarmento e Souza PACHECO, Paulo MÜLLER, Delson João COSTA, Leandro Eduardo KLÜPPEL, Nelson Luis Barbosa REBELLATO

O deslocamento de terceiros molares superiores para dentro do seio maxilar é uma das complicações trans-operatórias que podem ocorrer quando a remoção destes dentes é realizada. O diagnóstico diferencial para análise da localização do dente deverá ser feita através de exames por imagens, averiguando a posição e o envolvimento deste com o seio maxilar, visto que há a possibilidade do elemento dentário estar deslocado para o espaço pterigopalatino. $O$ trabalho apresenta 0 relato do caso da paciente O.S., submetida à cirurgia para remoção de um terceiro molar superior esquerdo incluso que foi deslocado para o interior do seio maxilar. A intenção é demonstrar como foi feito este diagnóstico, a técnica cirúrgica utilizada e o controle do caso a longo prazo. O acesso através da parede lateral do seio maxilar e a manutenção da lâmina cortical com levantamento da mucosa do seio mostra-se uma técnica eficiente, permitindo um bom reparo ósseo, demonstrado pela radiografia e pelo quadro clínico pós-operatório da paciente.

Palavras-chave: seio maxilar; cirurgia bucal; dente não-erupcionado 